\title{
Recurrent ventricular tachycardia associated with anomalous left coronary artery from the pulmonary artery in a child managed by revascularisation and map-guided endocardial resection
}

\author{
JANET M MCCOMB, RICHARD VINCENT, * COLIN J HILTON \\ From the Regional Cardiothoracic Centre, Freeman Hospital, Newcastle upon Tyne and $\star$ Royal Sussex Coun \\ Hospital, Brighton
}

SUMMARY A 13 year old girl with recurrent ventricular tachycardia that occurred in association with anomalous origin of the left coronary artery from the pulmonary artery is described. Such $\vec{a}$ arrhythmia has not been described before. Ligation of the anomalous left coronary artery led 80 more frequent episodes of ventricular tachycardia with evidence of myocardial ischaemia. She wass successfully managed by revascularisation (to establish a two coronary system) and map-guide्gd left ventricular aneurysmectomy.

Anomalous origin of the left coronary artery arising from the main pulmonary artery is a rare congenital anomaly that is often fatal in infancy. ${ }^{1}$ Myocardial ischaemia is common and infarction may occur, as may mitral regurgitation. ${ }^{1}$ The commonest mode of presentation is cardiac failure in infancy, but sudden death may occur both in children and adults with or without previous symptoms. ${ }^{1-3}$ In a review of 147 patients, sudden death was reported in 11 , occurring after exertion in six. ${ }^{1}$ Eight had been symptom free. Sudden death in these patients is thought to be caused by ventricular arrhythmias, ${ }^{12}$ although such arrhythmias have rarely been recorded. ${ }^{45}$

Management is controversial, with both medical and surgical treatment giving poor results, ${ }^{6}$ although a comparison was difficult because of bias in the selection of patients. ${ }^{6}$ There have been various sur-

Requests for reprints to Dr Janet M McComb, Regional Cardiothoracic Centre, Freeman Hospital, Newcastle upon Tyne NE7 7DN. gical approaches, although evidence suggests that revascularisation, with establishment of a two corong ary system, is the best option. ${ }^{78}$

We describe a 13 year old girl who is unusual several respects. She has survived to adolescence, despite a mortality for this condition in infancy of $80 \mathrm{~F}$ $90 \% .{ }^{13}$ She presented with recurrent ventricular arrhythmias, which increased in frequency after ligation of the anomalous left coronary artery. Fur ther recurrence of arrhythmias was prevented by surgical revascularisation with map-guided ven tricular aneurysmectomy.

\section{Case report}

This 13 year old girl presented initially at the age three months when she became cyanosed and dysp noeic. She was found to be in heart failure with tachycardia, cardiomegaly, and hepatomegaly. Sie improved gradually after treatment with digoxifo, which was subsequently stopped.

She remained well until the age of 11 when during 
gymnastics she had an episode of ventricular tachycardia with syncope, chest pain, and dyspnoea (fig 1). After she was admitted to her local hospital an apical systolic murmur was heard. The electrocardiogram showed $Q$ waves in leads $I$ and $\mathrm{QVL}$ with loss of $R$ wave amplitude and non specific ST-T wave changes in the lateral chest leads (fig 2). The chest $x$ ray showed moderate cardiac enlargement and the echocardiogram showed "slight dilatation of the left ventricle with some hypokinesia." Atenolol $25 \mathrm{mg}$ daily was started and later was increased to $50 \mathrm{mg}$ twice a day. Five months later, after a sudden fright she had a further episode of tachycardia, which terminated spontaneously after 45 minutes. After this, she was able to exercise on the treadmill according to the standard Bruce protocol for 14

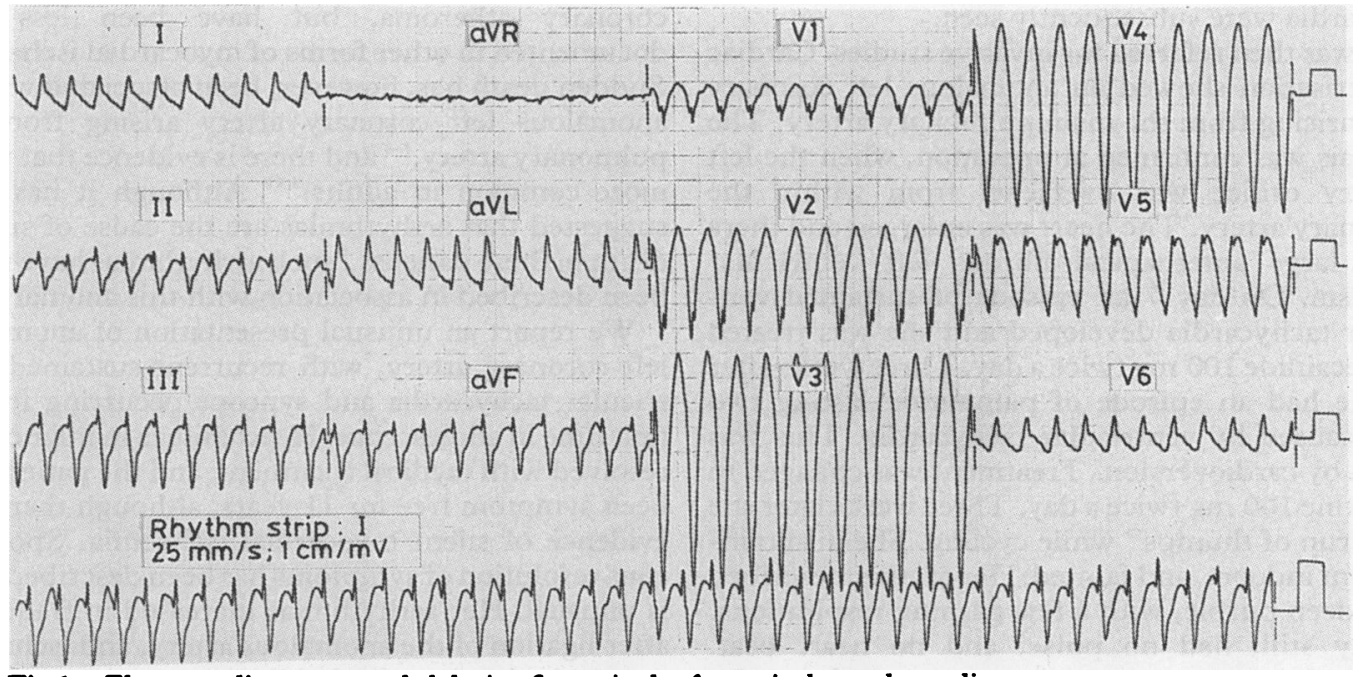

Fig 1 Electrocardiogram recorded during first episode of ventricular tachycardia.

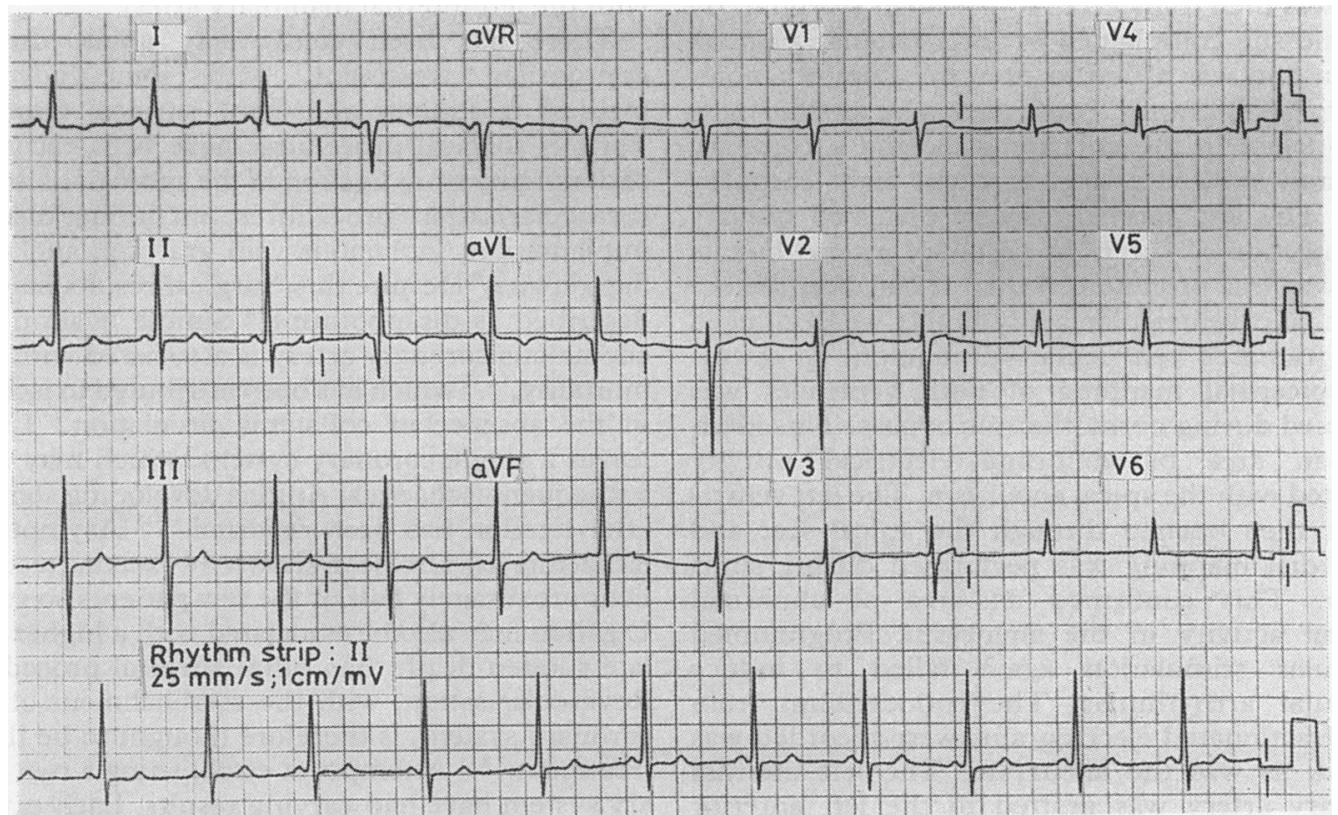

Fig 2 Electrocardiogram recorded during sinus rhythm. 
minutes, the heart rate rising from 67 to 166 beats per minute. Asymptomatic ST depression developed in the inferior leads and resolved during recovery. Ventricular bigeminy was seen at the termination of exercise. One week later, she complained of mild discomfort in the left arm, legs, and chest, with muscle pains and headache. She went swimming, and after two lengths tachycardia and clutching chest pain developed, which radiated to the back and was eased by glyceryl trinitrate. Runs of ventricular tachycardia were subsequently seen.

She was then referred for invasive studies. Cardiac catheterisation showed an anomalous left coronary artery arising from the main pulmonary artery. The diagnosis was confirmed at operation, when the left coronary orifice was oversewn from within the pulmonary artery. The heart was enlarged and there was a large anteroapical fibrous left ventricular aneurysm. On day 7 an episode of sustained ventricular tachycardia developed and she was treated with flecainide $100 \mathrm{mg}$ twice a day. Three weeks after this she had an episode of palpitation lasting two hours caused by ventricular tachycardia. This was treated by cardioversion. Treatment was changed to mexiletine $100 \mathrm{mg}$ twice a day. Three weeks later she felt "a run of thumps" while cycling. She dismounted, went indoors, and fainted. Her mother described her as deep purple, with a few gasping respirations. She lay still, had no pulse, and no heart beat. Cardiopulmonary resuscitation was started and she recovered within 30 seconds.

She was then transferred to Freeman Hospital. By this time she complained of interscapular pain on exertion and was afraid to exercise. Dipyridamolethallium scintigraphy confirmed a reversible perfusion defect in the anterior wall, and a coronary angiogram showed a large tortuous right coronary artery. The left coronary artery opacified quickly after injection of the right coronary artery, but its filling was less pronounced than it had been before ligation. No ventricular arrhythmias were induced by programmed ventricular stimulation. At operation, epicardial mapping of both ventricles was performed during normothermic bypass. This identified an area of abnormal electrical activity associated with the apical aneurysm. The left ventricle was then opened through the apical scar and endocardial mapping was performed during sinus rhythm. This confirmed an area of abnormal electrical activity in the aneurysm. Programmed ventricular stimulation again failed to induce ventricular arrhythmias. The endocardium from which fractionated electrograms were recorded was resected, as was the aneurysm. The left internal mammary artery was grafted to the left anterior descending coronary artery during cold cardioplegia.
Postoperatively she made a good recovery. Subsequently, she has done well, growing $11 \mathrm{~cm}$ with three months. She is taking no medication, is exercising normally, has no angina, and there has been no recurrence of her arrhythmia.

\section{Discussion}

Malignant ventricular arrhythmias are a well recog nised sequel of ischaemic heart disease caused coronary atheroma, but have been less wejl documented in other forms of myocardial ischaemis Sudden death has, however, been associated with an anomalous left coronary artery arising from the pulmonary artery, ${ }^{1-3}$ and there is evidence that this ${ }^{3} 3$ more common in adults. ${ }^{238}$ Although it has been suggested that arrhythmias are the cause of suddeg death in these patients, 9 such arrhythmias have rarefy been described in association with this anomaly. ${ }^{45}$

We report an unusual presentation of anomalous left coronary artery, with recurrent sustained velotricular tachycardia and syncope occurring for the first time in adolescence. Heart failure in infancy ha्द्य resolved with medical treatment, and the patient hapt been symptom free for 11 years, although there was evidence of silent myocardial ischaemia. Spontareg eous resolution of symptoms has been described ${ }^{10}$ but is unusual. Her arrhythmias increased in frequeng after ligation of the anomalous artery, and ischaem was again demonstrated. All her symptoms resolved after endocardial resection and revascularisation with the left internal mammary artery.

There has been controversy about the most appropriate treatment, with some advocating medical treatment ${ }^{6}$ and some surgical treatment Various surgical procedures have been recommen ded, ranging from ligation of the anomalous artery revascularisation procedures, including direct ros. implantation, saphenous vein grafting, and arteriä flap repairs. ${ }^{8}$ Despite this, surgical results have beeg described as disappointing. ${ }^{6}$ Simple ligation of the anomalous coronary artery is associated with a high mortality, ${ }^{5611}$ which has been attributed to ischaemi in the absence of collateral circulation. ${ }^{7}$ Ligation leaves a single coronary system, which may lead to subsequent ischaemia. Angina developing some time after ligation has been reported. ${ }^{11-13}$ Asymptomatis ischaemia has also been shown by exercise testing ${ }^{11-3}$ in approximately half of the few patients so studied Ligation may also be associated with a higher risk of late sudden death than other surgical procedures. $\frac{\text { P }}{O}$ Revascularisation, with the establishment of a two coronary system, is therefore thought to be the besit treatment. ${ }^{711}$ Attempts at establishing a two corons ary system have had varying results. Early attempts used saphenous vein grafting to the anomalous lefe 
coronary artery after ligation. ${ }^{12}$ Over 30 patients with saphenous vein grafts have been reported. Grafts were shown to be patent postoperatively in 11 patients, ${ }^{8121516}$ and were known to be occluded in five $(31 \%))^{891213}$ Various other methods of revascularisation have been described, ${ }^{7}$ but none was appropriate in our patient because of the previous ligation. The left internal mammary artery was therefore used to graft the anomalous coronary artery. This technique, not previously described in this condition, satisfactorily established a two coronary system, and may remain patent for longer than a saphenous vein graft.

Map-guided left ventricular endocardial resection was performed in addition to bypass grafting in our patient, as a further antiarrhythmic measure. Others have performed aneurysmectomy ${ }^{17}$ or left ventricular resection ${ }^{79}$ in a few patients, presumably because of heart failure, but a map-guided procedure has not been described before.

This report describes ventricular tachycardia in association with an anomalous left coronary artery, and emphasises the importance of appropriate management of ischaemia in the treatment of this condition.

\section{References}

1 Wesselhoeft H, Fawcett JS, Johnson AL. Anomalous origin of the left coronary artery from the pulmonary trunk. Its clinical spectrum, pathology, and pathophysiology based on a review of 140 cases with seven further cases. Circulation 1968;38:403-25.

2 George JM, Knowlan DM. Anomalous origin of the left coronary artery from the pulmonary artery in an adult. New Engl J Med 1959;261:993-8.

3 Wilson CL, Dlabal PW, Holey ield RW, Akins CW, Knauf DG. Anomalous origin of left coronary artery from pulmonary artery. Case report and review of literature concerning teenagers and adults. $J$ Thorac Cardiovasc Surg 1977;73:887-93.

4 Wright NL, Baue AE, Baum S, Blakemore WS, Zinsser HF. Coronary artery steal due to an anomalous left coronary artery originating from the pulmonary artery. J Thorac Cardiovasc Surg 1970;59:461-7.

5 Askenazi J, Nadas AS. Anomalous left coronary artery originating from the pulmonary artery. Report on 15 cases. Circulation 1975;51:976-87.
6 Driscoll DJ, Nihill MR, Mullins CE, Cooley DA, McNamara DG. Management of symptomatic infants with anomalous origin of the left coronary artery from the pulmonary artery. Am J Cardiol 1981;47:642-8.

7 Vouhe PR, Baillot-Vernant F, Trinquet F, et al. Anomalous left coronary artery from the pulmonary artery in infants. Which operation? When? $J$ Thorac Cardiovasc Surg 1987;94:192-9.

8 Arciniegas E, Farooki ZQ, Hakimi M, Green EW. Management of anomalous left coronary artery from the pulmonary artery. Circulation 1980;62(suppl 1): 1-180-9.

9 Moodie DS, Fyfe D, Gill CC, et al. Anomalous origin of the left coronary artery from the pulmonary artery (Bland-White-Garland syndrome) in adult patients: long-term follow-up after surgery. Am Heart $J$ 1983;106:381-8.

10 Ihenacho HNC, Singh SP, Astley R, Parsons CG. Anomalous left coronary artery. Report of an unusual case with spontaneous remission of symptoms. $\mathrm{Br}$ Heart $J$ 1973;35:562-5.

11 Bunton R, Jonas RA, Lang P, Rein AJJT, Castenada AR. Anomalous origin of left coronary artery from pulmonary artery. Ligation versus establishment of a two coronary artery system. J Thorac Cardiovasc Surg 1987;93:103-8.

12 El-Said GM, Ruzyllo W, Williams RL, et al. Early and late result of saphenous vein graft for anomalous origin of left coronary artery from pulmonary artery. Circulation 1973;47\&48(suppl III): 2-6.

13 Menahem S, Venables AW. Anomalous left coronary artery from the pulmonary artery: a 15 year sample. Br Heart J 1987;58:378-84.

14 Shrivastava S, Castenada A, Moller JH. Anomalous left coronary artery from the pulmonary trunk. Longterm follow-up after ligation. $J$ Thorac Cardiovasc Surg 1978;76:130-4.

15 Laborde $F$, Marchand $M$, Leca F, Jarreau $M-M$, Dequirot A, Hazan E. Surgical treatment of anomalous origin of the left coronary artery in infancy and childhood. Early and late results in 20 consecutive cases. J Thorac Cardiovasc Surg 1981;82: 423-8.

16 Evans JJ, Phillips JF. Origin of the left anterior descending coronary artery from the pulmonary artery, 3 year angiographic follow-up after saphenous vein bypass graft and proximal ligation. $\mathrm{J} \mathrm{Am} \mathrm{Coll}$ Cardiol 1984;3:219-24.

17 Turina M, Real F, Meier W, Senning A. Left ventricular aneurysmectomy in a 4-month-old infant. Alternative method of treatment of anomalous left coronary artery. J Thorac Cardiovasc Surg 1974;67:915-9. 